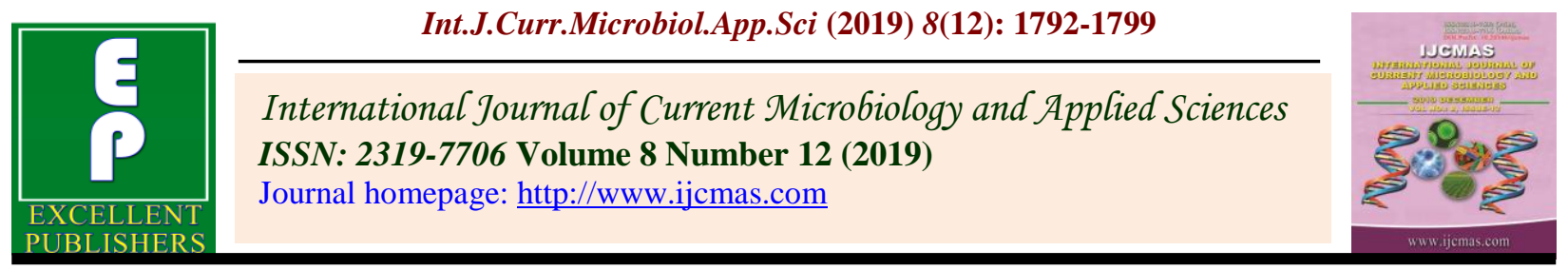

Original Research Article

https://doi.org/10.20546/ijcmas.2019.812.215

\title{
Effect of Substrate Treatment Methods on Yield of Pleurotus spp.
}

\author{
Varsha Kerketta*, C. S. Shukla, H. K. Singh, Anurag Kerketta, Veer Singh and Tamin
}

Department of Plant Pathology, College of Agriculture, IGKV, Raipur, C.G., India

*Corresponding author

\section{Keywords}

Oyster mushroom, Pleurotus species, Substrate pasteurization, Carbendazim, Formaldehyde

Article Info

Accepted:

15 November 2019

Available Online:

10 December 2019

\section{A B S T R A C T}

An experiment was conducted in February (2018) to know the effect of different methods of substrate treatment (carbendazim + formaldehyde, hot water, lime $2 \%$ and plane water) on spawn run, pin head initiation and yield of Pleurotus spp. on wheat straw substrate. The results are clearly indicates that on an average time for spawn run period was significantly quickest (7.25 days) noticed in species PL-17-12, while PL17-07 took more (14.25 days) time for spawn run. Among the evaluated different methods of substrate treatment, the average period recorded for spawn run was statistically differed and it was significantly less (9.94 days) recorded in carbendazim + formaldehyde followed by hot water and lime 2\% (10 days) and which were at par with each other. While more (11.80 days) period taken by plane water. Interaction of species $\times$ substrate treatment method also showed significant difference for spawn run period of Pleurotus species. PL-17-12 required minimum (7 days) period for spawn run with carbendazim + formaldehyde, hot water and lime $2 \%$ than other combination and maximum (16.33 days) period taken by PL-17-07 with plane water. The average days for pinhead initiation in different species of Pleurotus, recorded earlier (2.91 days) pinhead initiation was recorded in species PL-17-11 and it was significantly delayed (8.25 days), in PL-17-10. In different method of substrate treatment, faster pinhead initiation was found in hot water treated substrate (4.55 days) while it was took maximum (5.36 days) time in carbendazim + formaldehyde. On an interaction, pinhead initiation was quickest (2.33 days) found in species PL-17-12 with hot water treatment than other combination and more (9.33 days) period taken by carbendazim + formaldehyde and plane water in PL-17-07. The average yield of different species with substrate treatment varied significant with each other. The significantly higher (532.91 gm) yield was recorded in species PL-17-11 while PL-17-10 gave significant lower yield (159.56 gm). On different substrate treatment maximum yield (398.75 gm) was recorded in hot water treatment method and minimum yield (174.44 gm) was found in plane water. Interaction of species $\times$ substrate treatment method also showed significant differences in yield. The highest yield was recorded in species PL-17-11 (615.0 gm) with BE $123 \%$ in carbendazim + formaldehyde followed by hot water (595.0 gm) with BE $119 \%$ and lime $2 \%$ (591.0 gm) with BE $118.2 \%$ and they were statistically at par with each other, whereas, plane water gave minimum yield (48.33 gm) with BE $9.6 \%$ in species PL-17-10. 


\section{Introduction}

Mushrooms are becoming extremely important and common in human diets, due to their source of nutrition and medicinal characteristics. Pleurotus mushrooms, commonly known as oyster mushrooms, grow in the wild in tropical, subtropical and temperate regions and are easily artificially cultivated. Among all mushrooms, Pleurotus ostreatus is very popular species of oyster mushroom. It can be cultivated artificially for suitable weather and climatic condition. Mushroom substrates are contaminated by various kinds of mycoflora. Most of them act as competitor moulds thereby spawn run is contrary affected either by competition for food material or through production of toxic substances.

There are Several causes were reported for mushroom substrate contamination. Sterilization of substrates is much more appropriate method for effective and smooth cultivation of mushroom to remove the existence of microorganisms. The common weed molds associated with edible mushrooms can be controlled by several treatments of substrates of mushrooms. Substrates for commercial production of Pleurotus ostreatus must be pasteurized in order to minimize the contamination. Among the substrate treatments, hot water treatment is very common method among the farmers but the farmers have lack of appropriate knowledge of other sterilization methods of substrates for example lime which is cheap and easily available, we can also use chemical for sterilization. The substrates for cultivating edible mushrooms e.g. Pleurotus ostreatus, has been reported to require of pre-treatment in order to enhance growth of the mushroom mycelium by the reducing of other microorganisms. The aim of this research is to estimate the growth of pathogen on substrates after pasteurization with different methods e.g. hot water, chemical, lime, control to know which of them are more effective to avoid contamination and to determine the influence on yield attributes of oyster mushroom during mushroom production.

\section{Materials and Methods}

Wheat straw which is considered successful substrate for the cultivation of Pleurotus spp. and for being abundantly available in village area was used as experimental substrate for growing oyster mushroom. Different method of pasteurization were followed during experiment viz., Chemical (carbendazim), hot water, lime (2\%) and plane water (control) methods were evaluated to see their impact on growth and yield of different Pleurotus species and substrate without pasteurization was used as control. During experiment wheat straw substrate was taken and treated with different methods. Spawning was done through layer method (4\% on wet weight basis) and shifted to mushroom growing unit. 5replications of each treatment with 4 bags per replications were maintained and observations on yield per unit of straw were recorded.

\section{Biological efficiency}

The yield was expressed in biological efficiency and calculated using the formula (Chang et al., 1981).

$$
\begin{aligned}
& \text { Biological efficiency\% } \\
& =\frac{\text { Fresh weight of mushroom }}{\text { Dry weight of substates }} X 100
\end{aligned}
$$

\section{Results and Discussion}

Pasteurization is a method of eradication of harmful microorganisms from any substrate that make it contaminated free. There are many methods pasteurization have been developed to treat mushroom substrate for obtained better yield of Pleurotus spp. 
Pasteurization plays a role in yield maximization of mushroom by disinfecting the substrate from contamination.

Following tables explains about various methods of pasteurization which directly increase the yield and B.E and various yield attributing characters. Effects of substrate Pasteurization methods on spawn run of different Pleurotus spp. were compared between treatment and sub treatments. Among the evaluated species on an average there were significantly difference noticed was earlier spawn run was observed in PL-17-12 (7.25 days) at par with PL-17-06 (7.66 days) followed by PL-17-08 (7.83days), whereas maximum days for spawn run was taken by PL-17-07 (14.25 days) andPL-17-13 (13.41 days).Among the evaluated pasteurization methods on an average fastest spawn run was noted in chemical pasteurization method $(9.94$ days) followed by hot water pasteurization method (10.00 days) and lime pasteurization method (10.00days) and maximum days required by plane water (control) (11.80 days).In interaction, between evaluated Pleurotus spp. And methods of pasteurization significantly less (7.00days) period for spawn run taken by PL-17-12 in all the methods of substrate pasteurization except control which required (8.0 days) for spawn run, the data are present in table 1 .

Table.1 Effect of substrate treatment methods on spawn run of different species of Pleurotus

\begin{tabular}{|c|c|c|c|c|c|}
\hline \multirow[t]{2}{*}{ SPECIES } & \multicolumn{4}{|c|}{ SPAWN RUN (days) } & \multirow[t]{2}{*}{ MEAN } \\
\hline & CHEMICAL* & $\begin{array}{c}\text { HOT } \\
\text { WATER* }\end{array}$ & LIME* & $\begin{array}{c}\text { PLANE } \\
\text { WATER*(control) }\end{array}$ & \\
\hline Pl-17-01 & 9.000 & 9.00 & 9.00 & $10.66^{* *}$ & 9.41 \\
\hline Pl-17-02 & 8.66 & 8.66 & 9.00 & 12.00 & 9.58 \\
\hline Pl-17-03 & 10.33 & 10.66 & 10.66 & 13.66 & 11.33 \\
\hline Pl-17-04 & 9.00 & 9.00 & 9.33 & 12.00 & 9.83 \\
\hline Pl-17-05 & 12.33 & 12.00 & 13.00 & 14.33 & 12.91 \\
\hline Pl-17-06 & 7.33 & 7.33 & 7.66 & 8.33 & 7.66 \\
\hline Pl-17-07 & 15.33 & 15.33 & 10.00 & 16.33 & 14.25 \\
\hline Pl-17-08 & 7.66 & 7.33 & 8.00 & 8.33 & 7.83 \\
\hline Pl-17-09 & 11.33 & 10.67 & 11.33 & 11.33 & 11.16 \\
\hline Pl-17-10 & 12.00 & 13.33 & 14.00 & 14.33 & 13.41 \\
\hline Pl-17-11 & 9.33 & 9.67 & 11.00 & 12.33 & 10.58 \\
\hline PI-17-12 & 7.00 & 7.00 & 7.00 & 8.00 & 7.25 \\
\hline \multirow[t]{5}{*}{ MEAN } & 9.94 & 10.00 & 10.00 & 11.80 & \\
\hline & & & SEm \pm & CD $(5 \%)$ & \\
\hline & & Factor $(\mathbf{A}) *$ & 0.22 & 0.63 & \\
\hline & & Factor $(\mathbf{B}) *$ & 0.39 & 1.09 & \\
\hline & & Factor $(A \times B)$ & 0.78 & 2.19 & \\
\hline
\end{tabular}

*Average of three replication, **growth in patches, *Factor A (pasteurization method), *Factor B (species) 
Table.2 Effect of substrate treatment methods on pin head initiation of different species of Pleurotus

\begin{tabular}{|c|c|c|c|c|c|}
\hline \multirow[t]{2}{*}{ Species } & \multicolumn{4}{|c|}{ PIN HEAD INITIATION (days) } & \multirow[t]{2}{*}{ MEAN } \\
\hline & $\begin{array}{l}\text { CHEMICA } \\
\text { L }^{*}\end{array}$ & $\begin{array}{c}\text { HOTWATE } \\
\mathbf{R}^{*}\end{array}$ & LIME* & $\begin{array}{c}\text { PLANE } \\
\text { WATER*(control) }\end{array}$ & \\
\hline PL-17-01 & 5.00 & 5.00 & 5.66 & $0.00 * *$ & 3.91 \\
\hline PL-17-02 & 5.00 & 5.00 & 6.00 & 4.00 & 5.00 \\
\hline PL-17-03 & 5.00 & 6.00 & 5.00 & 5.66 & 5.41 \\
\hline PL-17-04 & 4.66 & 5.00 & 5.33 & 6.33 & 5.33 \\
\hline PL-17-05 & 4.66 & 4.33 & 4.33 & 5.00 & 4.58 \\
\hline PL-17-06 & 6.00 & 4.66 & 5.00 & 3.66 & 4.83 \\
\hline PL-17-07 & 9.33 & 3.66 & 4.33 & 9.33 & 6.66 \\
\hline PL-17-08 & 4.33 & 4.00 & 4.00 & 3.33 & 3.91 \\
\hline PL-17-09 & 5.00 & 4.00 & 4.33 & 5.66 & 4.75 \\
\hline PL-17-10 & 9.00 & 7.66 & 8.66 & 7.66 & 8.25 \\
\hline PL-17-11 & 3.00 & 3.00 & 2.66 & 3.00 & 2.91 \\
\hline PL-17-12 & 3.33 & 2.33 & 4.00 & 3.00 & 3.16 \\
\hline \multirow[t]{5}{*}{ MEAN } & 5.36 & 4.55 & 4.94 & 4.72 & \\
\hline & & SEm \pm & CD $(5 \%)$ & & \\
\hline & $\operatorname{Factor}(\mathbf{A}) *$ & 0.12 & 0.33 & & \\
\hline & Factor $(\mathbf{B})^{*}$ & 0.20 & 0.58 & & \\
\hline & Factor $A \times B$ ) & 0.41 & 1.17 & & \\
\hline
\end{tabular}

*Average of three replication, ** growth in patches on bag

Fig.1 Yield of different species of Pleurotus on hot water treated substrate

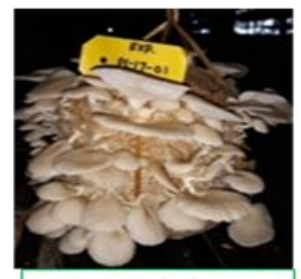

PL-17-01

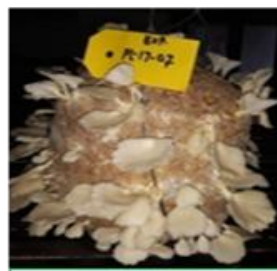

PL-17-07

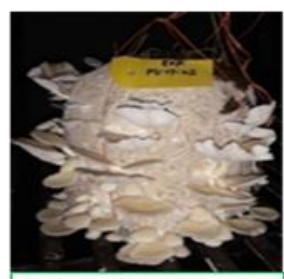

PL-17-02

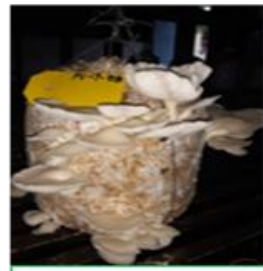

PL-17-08

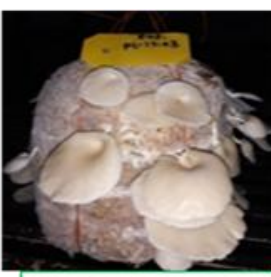

PL-1 7 -03

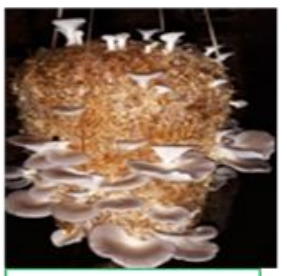

PL-17-09

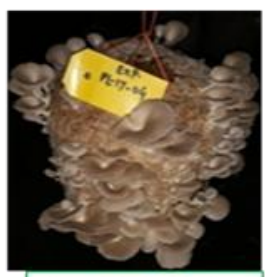

PI-1 7 -04

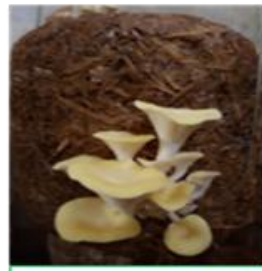

PL-17-10

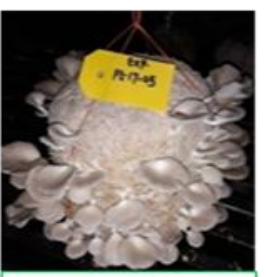

PL-17-05

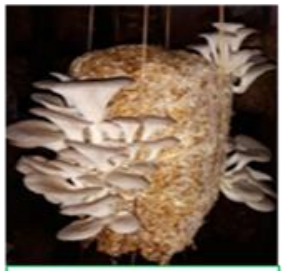

PL-17-11

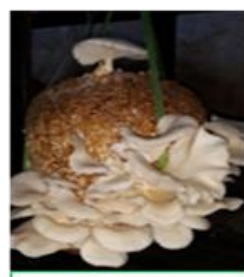

PL-17-06

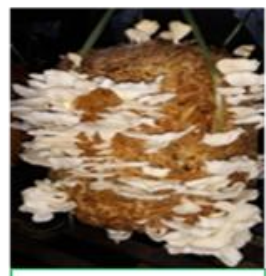

PL-17-12 
Table.3 Effect of substrate treatment methods on yield of different species of Pleurotus

\begin{tabular}{|c|c|c|c|c|c|c|c|c|c|}
\hline \multirow[t]{3}{*}{ Species } & \multicolumn{8}{|c|}{ YIELD* $($ gm $)$} & \multirow[t]{3}{*}{ MEAN } \\
\hline & \multicolumn{2}{|c|}{ CHEMICAL } & \multicolumn{2}{|c|}{ HOT WATER } & \multicolumn{2}{|c|}{ LIME } & \multicolumn{2}{|c|}{$\begin{array}{c}\text { PLAIN } \\
\text { WATER*(control) }\end{array}$} & \\
\hline & $\begin{array}{l}\text { Yield } \\
(\mathrm{gm})^{*}\end{array}$ & $\begin{array}{l}\text { B.E. } \\
(\%)\end{array}$ & Yield $(\mathrm{gm})^{*}$ & $\begin{array}{l}\text { B.E. } \\
(\%)\end{array}$ & $\begin{array}{l}\text { Yield } \\
(\mathrm{gm})^{*}\end{array}$ & $\begin{array}{l}\text { B.E. } \\
(\%)\end{array}$ & $\begin{array}{l}\text { Yield } \\
(\mathrm{gm})^{*}\end{array}$ & B.E. $(\%)$ & \\
\hline PL-17-01 & 395.00 & 79.0 & 418.33 & 83.6 & 390.00 & 78.0 & 000.00 & 0.00 & 300.83 \\
\hline PL-17-02 & 383.33 & 76.6 & 415.00 & 83.0 & 260.00 & 72.0 & 213.33 & 42.0 & 317.91 \\
\hline PL-17-03 & 390.00 & 78.0 & 446.66 & 89.2 & 246.66 & 49.2 & 215.00 & 43.0 & 324.58 \\
\hline PL-17-04 & 380.00 & 76.00 & 360.00 & 72.0 & 325.00 & 65.0 & 215.00 & 43.0 & 320.00 \\
\hline PL-17-05 & 383.33 & 76.6 & 383.33 & 76.6 & 330.00 & 66.0 & 123.33 & 24.6 & 305.00 \\
\hline PL-17-06 & 405.00 & 81.0 & 466.66 & 93.3 & 333.33 & 66.6 & 230.00 & 46.0 & 358.75 \\
\hline PL-17-07 & 226.66 & 45.2 & 251.66 & 50.2 & 285.00 & 57.0 & 136.66 & 27.2 & 225.00 \\
\hline PL-17-08 & 425.00 & 85.0 & 481.66 & 96.2 & 406.66 & 81.2 & 220.00 & 44.0 & 383.33 \\
\hline PL-17-09 & 361.66 & 72.2 & 333.33 & 66.6 & 288.33 & 57.6 & 70.00 & 14.0 & 263.33 \\
\hline PL-17-10 & 253.33 & 50.6 & 170.00 & 34.0 & 165.00 & 33.0 & 48.33 & 9.6 & 159.56 \\
\hline PL-17-11 & 615.00 & 123.0 & 595.00 & 119 & 591.66 & 118.2 & 330.00 & 66.6 & 532.91 \\
\hline PL-17-12 & 431.66 & 86.2 & 463.33 & 92.6 & 283.33 & 56.6 & 291.66 & 58.2 & 367.50 \\
\hline \multirow[t]{5}{*}{ MEAN } & 387.50 & & 398.75 & & 325.41 & & 174.44 & & \\
\hline & & & FACTORS & $\begin{array}{l}\text { SE(m) } \\
\quad \pm\end{array}$ & CD (5\%) & & & & \\
\hline & & & $\operatorname{Factor}(\mathbf{A})^{*}$ & 9.26 & 26.04 & & & & \\
\hline & & & Factor $(\mathbf{B})^{*}$ & 16.04 & 45.11 & & & & \\
\hline & & & $\begin{array}{c}\text { Factor } \\
(\mathrm{A} \times \mathrm{B})\end{array}$ & 32.09 & 90.22 & & & & \\
\hline
\end{tabular}

(*)Average of three replication 
Fig.2 Effect of different substrate treatment method on spawn run of different spp. of Pleurotus

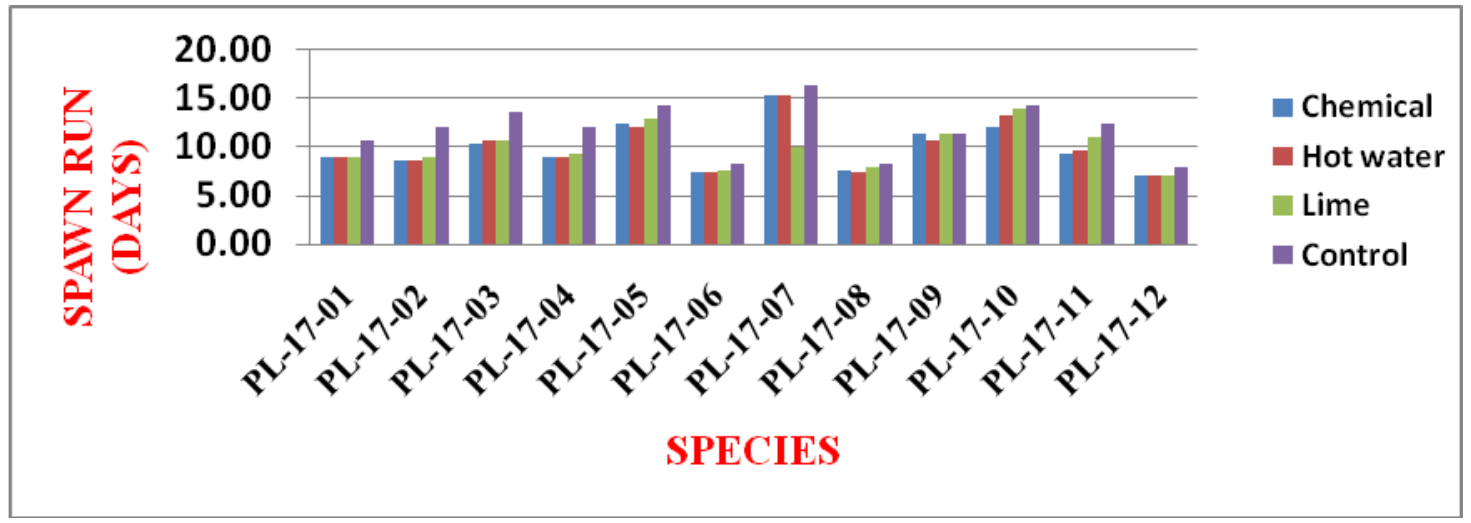

Fig.3 Effect of different substrate treatment method on pin head initiation of different spp. of Pleurotus

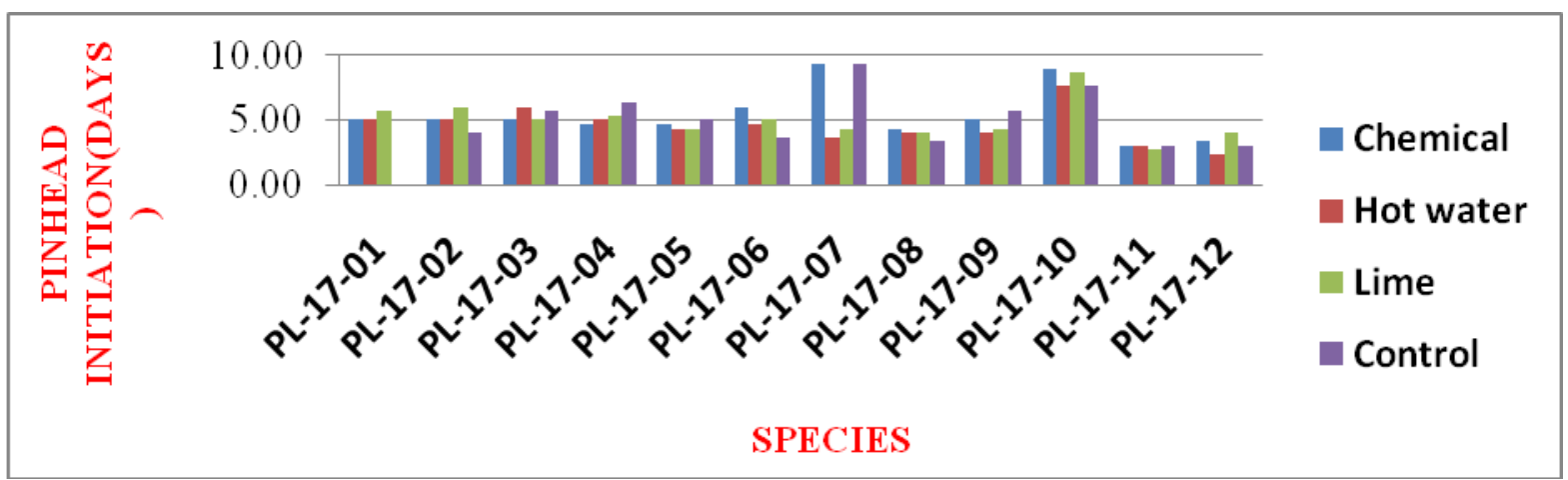

Fig.4 Effect of substrate treatment method on yield of different spp. of Pleurotus

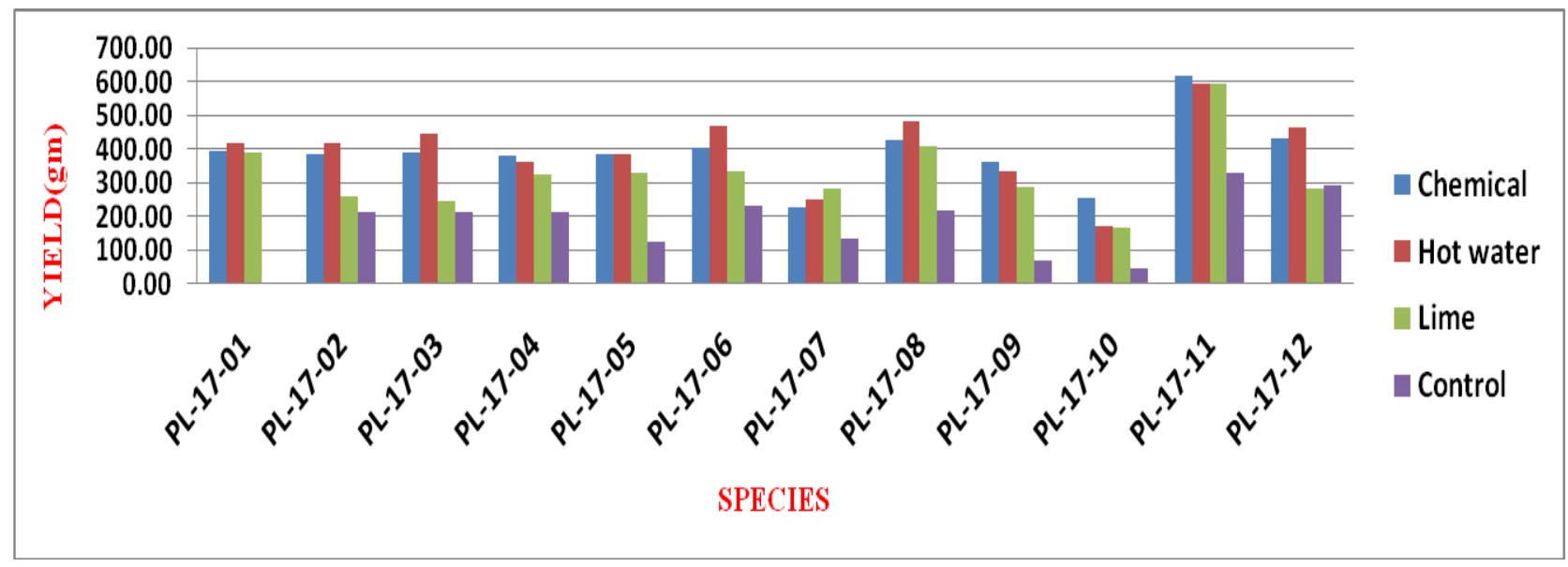

The different methods of substrate pasteurization methods were studied on primordial initiation in different species of
Pleurotus and data are given in table 2. From the table it is evident that different methods of substrate pasteurization greatly influenced the 
initiation of primordial in studied species of Pleurotus. On an average among the evaluated species of Pleurotus PL-17-11 (2.91 days) showed quickest (2.91 days) primordial initiation and it was late appeared in PL-1710(8.25days). In evaluated methods of substrate pasteurization, hot water and plane water gave significantly earlier (4.55 and 4.72 days respectively) primordial initiation which at par statistically next was lime water(4.92 days) while chemical (5.36 days). In interaction, PL-17-11×lime pasteurization showed fastest primordial initiation (2.66days) while other required 3.00 days for primordial formation.

To know the effect of substrate pasteurization methods of different Pleurotus spp. Was studied and data are recorded for fresh yield and biological efficiency the data are given in Table 3. From the table the data is clear that among the evaluated species of Pleurotus, PL17-11 gave significantly highest $(532.91 \mathrm{gm})$ fresh yield and it was lowest recorded in PL$17-10$ (159.56gm). Among the evaluated methods of pasteurization, hot water pasteurization method (398.75 gm) and chemical pasteurization method (387.50 gm) and lowest in plane water (174.44 gm) fresh yield (Fig. 1-4).

On an interaction Among all evaluated species and pasteurization methods, PL-17-11 gave significantly superior obtained in $(615.00$ gm) yield with B.E. $123 \%$ in chemical pasteurization methods followed by PL-17$11(595.00 \mathrm{gm})$ with B.E.119\% in Hot water pasteurization method and PL-17-11 (591.66 gm) withB.E.118.2\% in lime pasteurization method while lowest yield obtained by PL-1710(48.33 gm) with B.E.(9.6\%) in plane water pasteurization method followed by PL-17-09 (70gm) with B.E. $14 \%$ in plane water pasteurization method. Kurtzman (2016) explained about benefits of pasteurization of mushroom substrate for better growth and higher yield of Pleurotus spp.
The obtained results are closely related with the findings of Ali et al., (2007) where they evaluated the effect of pasteurization methods in waste substrate on yield of oyster mushroom (Pleurotus spp.) cotton waste subordinate to different methods of pasteurization, namely with chemical pasteurization with formalin, steam, lime water and plane water (without pasteurization) used as (control) and concluded that steam pasteurization technique gave more yield of Pleurotus. Caral et al., also found more yield of Pleurotus spp. on physically sterilized substrate. The current results are related to Santiago Jaramillo Mejia et al., (2013), who concluded that chemical (carbendazim) treatment produced higher yields while hotwater pasteurization method reduced the yield of Pleurotus spp.

Chemical and hot water pasteurization method was found the best method for pasteurization of wheat straw. On the basis of performance of biological efficiency, economic yield and other yield attributes of oyster mushroom on chemical and hot water pasteurization method was better compared to lime, plane water treatment of wheat straw.

\section{References}

Ali, M. A., Hussain, S., Nawaz, R., Ahson, A. and Sidddiq, M. 2007. Effect of pasteurization techniques on mycelial growth of oyster mushroom, Pleurotus species. J. Agri. Res: 42(2):. 201- 207.

Bano, Z. and Rajarathnam, S. 1978. Studies on the cultivation of Pleurotus sajor-caju. Mushroom Journal, 115: 243-245.

Caral, D. and Palani, M. 2013. Comparative study of oyster mushroom (Pleurotus ostreatus) cultivation by physical and chemical method of sterilization using two different substrates. International Journal of Scientific \& Engineering Research, 4 (9): 898-902. 
Chang S. T. 2008. Overview of mushroom cultivation and utilization as functional foods. The Chines University press. Hong Kong.1-29 pp.

Chang ST, Miles PG. Edible Mushrooms and their Cultivation. 1st edition, ERC Press, Boca Raton, Florida USA, 1989; p: 345.

Hasan, N., Rahman, M. S., Nigar, S., Bhuiyan, M. Z. A. and Ara, N. (2010). Performance of oyster mushroom on different pretreated substrate, Int. J. Sustain. Crop Prod. Vol., 5(4), 16-24

Jaramillo Mejía, S., and Albertó, E. (2013). Heat treatment of wheat straw by immersion in hot water decreases mushroom yield in Pleurotus ostreatus.
Revista Iberoamericana de Micología, 30(2), 125-129.

Kurtzman, R. H. 2010. Pasteurization of mushroom substrate and other solids. African Journal of Environmental Science and Technology, 4(13): 936941.

Singh, R.P. and Dwivedi, R.R. 1991. Standardisation of substrate for production of Pleurotus sajor caju. Adv. Mushroom Sci. (Abstract), pp.36.

Vijay, B. and Sohi, H. S. (1987). Cultivation of oyster mushroom Pleurotus sajorcaju (Fr.). Singeron chemically sterilized wheat straw. Mush. J. tropics, 7: 67-75.

\section{How to cite this article:}

Varsha Kerketta, C. S. Shukla, H. K. Singh, Anurag Kerketta, Veer Singh and Tamin. 2019. Effect of Substrate Treatment Methods on Yield of Pleurotus spp. Int.J.Curr.Microbiol.App.Sci. 8(12): 1792-1799. doi: https://doi.org/10.20546/ijcmas.2019.812.215 